\title{
DIREITO INTERNACIONAL PRIVADO DAS SUCESSÕES NA UNIÃO EUROPEIA: A DETERMINAÇÃO DO DIREITO APLICÁVEL NO NOVO REGULAMENTO 650/2012, DE 4 DE JULHO DE 2012
}

\section{DERECHO INTERNACIONAL PRIVADO DE LAS SUCESIONES EN LA UNIÓN EUROPEA: LA DETERMINACIÓN DEL DERECHO APLICABLE EN EL NUEVO REGLAMENTO 650/2012, DE 4 DE JULIO DE 2012}

Carl Friedrich Nordmeier

Resumo: Com a entrada em vigor do Regulamento 650/2012, de 4 de julho de 2012, no âmbito da União Europeia, o direito internacional das sucessões foi harmonizado naquele processo de integração. O presente artigo analisa as regras de Direito Internacional Privado stricto sensu contidas no Regulamento. A residência habitual como principal fator de conexão é discutida, bem como o princípio da unidade da sucessão e a admissão do reenvio. Quanto a uma possível escolha da lei, cabe distinguir entre a escolha em si e a disposição por morte na qual ela está contida. A nacionalidade do defunto como ponto de conexão tem relevância particular neste contexto. As disposições por morte, sobretudo o testamento de mão comum e o pacto sucessório, são analisadas. A maioria das questões quanto a uma disposição por morte é respondida pelo estatuto sucessório hipotético. A escolha da lei aplicável a uma disposição por morte, bem como a sua forma, merecem atenção especial. Por fim, são debatidos dois problemas particulares que encontraram uma solução com o surgimento do Regulamento, quais sejam, o dos comorientes e o da herança vaga.

Resumen: Con la entrada en vigor del Reglamento 650/2012, de 4 de julio de 2012, en el ámbito de la Unión Europea, el derecho internacional de la sucesión se ha armonizado en aquel proceso de integración. Este artículo analiza las normas de derecho internacional privado stricto sensu

\footnotetext{
* Carl Friedrich Nordmeier, juíz de direito em Wiesbaden, Hessen, Alemanha, doutor em direito pela Universidade de Heidelberg, membro da Associação Luso-Alemão de Juristas, professor convidado do curso de especialização em Direito Internacional Privado, Público e Direito da Integração da Universidade Federal do Rio Grande do Sul, Porto Alegre, Brasil.
} 
contenidas en el Reglamento. El concepto de residencia habitual como el factor principal de conexión se discute, así como el principio de la unidad de la sucesión y la admisión del reenvío. En relación a una posible elección de la ley, es posible distinguir entre la propia elección y la disposición mortis causa en la que está contenida. La nacionalidad del fallecido como un punto de conexión tiene especial relevancia en este contexto. Las disposiciones mortis causa, sobre todo el testamento mancomunado y el pacto sucesorio, se analizan. La mayoría de las preguntas con respecto a una disposición mortis causa es respondida por el estatuto hipotético de la sucesión. La elección de la ley aplicable a la disposición mortis causa, así como su forma, merecen atención especial. De los problemas particulares que encontraron una solución en el Reglamento se presenta el de los comorientes y el de la sucesión vacante.

Palavras-chave: Conflito de leis, União Europeia, Sucessões, Unidade da sucessão, Europeização

Palabras clave: Conflicto de leyes; Unión Europea, Sucesiones, Unidad de la sucesión, Europeización

\section{INTRODUÇÃO}

A unificação do Direito Internacional Privado das Sucessões no nível europeu é um passo importante no processo de integração que inclui todos os ramos do DIP ${ }^{1}$. Ela foi atingida com a aprovação do Regulamento 650/2012, de 4 de julho de $2012^{2}$. O Regulamento é fruto de uma longa fase de preparação, iniciada por um estudo do Instituto Alemão de Notários em cooperação com os professores Lagarde e Dörner ${ }^{3}$. Um livro verde lançado em março de $2005^{4}$ antecedeu uma proposta de Regulamento da Comissão, que surgiu, então, em outubro de $2009^{5}$. Durante o processo legislativo, esta proposta sofreu várias

\footnotetext{
1 Sobre este processo ver JAEGER JUNIOR Augusto, NORDMEIER Carl Friedrich (2013) "Comunitarização do Direito Internacional Privado: paulatina harmonização de um âmbito jurídico”. In: SOUZA DEL’OLMO Florisbal de, COLER GIMENEZ Charlise Paula, MARCONATTO DAMO CERVI Taciana (eds.) Direitos Fundamentais e Cidadania: a busca pela efetividade. Campinas: Editora Millennium, p. 131-156.

2 Regulamento (UE) N 650/2012 do Parlamento Europeu e do Conselho de 4 de julho de 2012 relativo à competência, à lei aplicável, ao reconhecimento e execução das decisões, e à aceitação e execução dos atos autênticos em matéria de sucessões e à criação de um Certificado Sucessório Europeu. Jornal Oficial da União Europeia L 2012. n 201. p. 107. Retificado em Jornal Oficial da União Europeia L 2012. n 344. p. 3. E em Jornal Oficial da União Europeia L 2013. n 41. p. 16. 3 Ver os resultados do estudo em DÖRNER Heinrich, HERTEL Christian, LAGARDE Paul, RIERING Wolfgang (2005) "Auf dem Weg zu einem europäischen Internationalen Erb- und Verfahrensrecht". Praxis des Internationalen Privat- und Verfahrensrechts, 1. p. 1-8.

4 Livro Verde de Sucessões e Testamentos de 1.3.2005, COM (2005) 65 final.

5 Proposta de Regulamento do Parlamento Europeu e do Conselho relativo à competência, à lei aplicável, ao reconhecimento e execução das decisões e dos atos autênticos em matéria de sucessões e à criação de um Certificado Sucessório Europeu de 14.10.2009, COM (2009)
} 
modificações e complementações ${ }^{6}$. O resultado final é um Regulamento com 84 artigos e 83 considerandos. Ele consiste, basicamente, de quatro partes: a primeira trata, no Capítulo II do Regulamento (arts. 4-19), de questões da competência internacional; a segunda, no Capítulo III do Regulamento (arts. 20-38), ocupa-se com a determinação do direito aplicável; a terceira, nos Capítulos IV e V (arts. 39-61), é dedicada ao reconhecimento e à execução de decisões, atos autênticos e transações judiciais; e a quarta, no Capítulo V (arts. 62-72), introduz um inovador certificado sucessório europeu7. O Capítulo I (arts. 1-3) e o Capítulo VII (arts. 74-84) contêm regras gerais para a aplicação do Regulamento.

A presente contribuição trata somente das regras de Direito Internacional Privado stricto sensu, isto é, da questão como a lei aplicável é determinada. Como já referido, as regras relevantes encontram-se, basicamente, no Capítulo III do Regulamento 650/2012 (arts. 20-38) ${ }^{8}$.

Cabe referir, ainda, que o Regulamento 650/2012 entrou em vigor no dia 16 de agosto de 2012, de acordo com o seu art. 84, inciso 1. Ainda assim, as normas serão aplicáveis somente a partir de 17 de agosto de 2015, como reza o art. 84, inciso 2, do Regulamento 650/2012. Esta divergência permite aos interessados, sobretudo aos notários e aos advogados, conhecer as novas regras, que são, já pelo seu número, de grande complexidade. Vale mencionar, para fins de comparação, que o Direito Internacional Privado das Sucessões stricto sensu atualmente em vigor na Alemanha encontra-se regulado em apenas dois artigos na Lei de Introdução ao Código Civil alemão9. Já o Capítulo III do Regulamento compreende 19 artigos.

154 final. Da grande quantidade de publicações sobre a proposta são destacadas aqui: MAX PLANCK INSTITUTE FOR COMPARATIVE AND INTERNATIONAL PRIVATE LAW (2010) "Comments on the European Commission's Proposal for a Regulation of the European Parliament and of the Council on jurisdiction, applicable law, recognition and enforcement of decisions and authentic instruments in matters of succession and the creation of a European Certificate of Succession". Rabels Zeitschrift für ausländisches und internationales Privatrecht, 74, p. 522-720; ROTH Wulf-Henning (2011) "Der Vorschlag einer Verordnung zur Regelung des Internationalen Erbrechts". In: SCHMOECKEL Mathias, OTTE Gerhard (eds.) Europäische Testamentsformen. Baden-Baden: Nomos-Verlag, p. 13-30; e SÜß Rembert (2009) "Der Vorschlag der EG-Kommission zu einer Erbrechtsverordnung (Rom IV-Verordnung) vom 14. Oktober 2009". Zeitschrift für Erbrecht und Vermögensnachfolge, 12, p. 342-348.

6 Mais detalhadamente sobre o processo legislativo ver VOLLMER Peter W. (2012) "Die neue europäische Erbrechtsverordnung - ein Überblick". Zeitschrift für die Steuer- und Erbrechtspraxis, 9, p. 227-228.

7 Sobre este certificado ver BUSCHBAUM Markus, SIMON Ulrich (2012) "EuErbVO: Das Europäische Nachlasszeugnis”. Zeitschrift für Erbrecht und Vermögensnachfolge, 10, p. 525-530 e WILSCH Harald (2012) "EuErbVO: Die Verordnung in der deutschen Grundbuchpraxis". Zeitschrift für Erbrecht und Vermögensnachfolge, 10, p. 530-532.

8 As regras da competência internacional estão discutidas em DÖRNER Heinrich (2012) "EuErbVO: Die Verordnung zum Internationalen Erb- und Erbverfahrensrecht ist in Kraft!" Zeitschrift für Erbrecht und Vermögensnachfolge, 10, p. 505, 510-511. Ver também DUTTA Anatol (2013) "Das neue internationale Erbrecht der Europäischen Union - Eine erste Lektüre der Erbrechtsverordnung". Zeitschrift für das gesamte Familienrecht, 1, p. 4, 5-8.

9 Tratam-se dos arts. 25 e 26 da Einführungsgesetz zum Bürgerlichen Gesetzbuch. 


\section{ESTRUTURA DO CAPÍTULO III DO REGULAMENTO 650/2012 SOBRE A LEI APLICÁVEL}

Para um melhor entendimento das normas sobre a determinação da lei aplicável, é recomendável distinguir-se entre casos nos quais existe uma disposição por morte e os em que o falecido morreu sem deixar uma tal disposição, isto é, nos quais a sucessão está regulada somente por lei. As regras principais para o segundo caso estão nos arts. 21-23 Regulamento 650/2012, enquanto as normas relevantes para o primeiro caso encontram-se nos arts. 24-27 Regulamento 650/2012. O art. 20 Regulamento 650/2012 determina de maneira geral a aplicação universal do Regulamento, enquanto os arts. 28-33 Regulamento $650 / 2012$ preveem regras particulares para situações fáticas ou jurídicas especiais, por exemplo, para o problema da adaptação de direitos reais, no art. 31 Regulamento $650 / 2012^{10}$, ou para aquele dos comorientes, no art. 32 Regulamento 650/2012. Nos arts. 34-38 Regulamento 650/2012 constam normas que solucionam questões de Direito Internacional Privado, que não são específicas para o direito das sucessões. Assim, nomeadamente, aquelas sobre o reenvio (art. 34 Regulamento 650/2012), a ordem pública (art. 35 Regulamento 650/2012), o tratamento dos ordenamentos jurídicos plurilegislativos (arts. 36-37 Regulamento 650/2012) e o conflito de leis internas (art. 38 Regulamento 650/2012).

\section{DETERMINAÇÃO DA LEI APLICÁVEL}

A regra geral para a determinação da lei aplicável consta no art. 21, inciso 1 Regulamento 650/2012. Aplica-se a lei do Estado onde o falecido tinha a sua residência habitual no momento do óbito. Ainda assim, uma pessoa pode optar pela aplicação da lei do Estado de que é nacional no momento em que ela fizer a escolha da lei aplicável ou no momento do óbito.

Neste contexto, vale sublinhar que o Regulamento 650/2012 é de aplicação universal, como se lê no art. 20 Regulamento 650/2012. Isto significa que a lei a ser aplicada pode ser a de um Estado que não seja um Estado-Membro da União Europeia ${ }^{11}$, e, além disso, que o Regulamento é aplicável mesmo em situações nas quais o de cujus não tenha a nacionalidade de um Estado-Membro, nem residência habitual num tal Estado.

10 Sobre este ver SCHMIDT Jan Peter (2013) "Die kollisionsrechtliche Behandlung dinglich wirkender Vermächtnisse”. Rabels Zeitschrift für ausländisches und internationales Privatrecht, 77 , p. 2, 16 e seg.

11 Sobre a noçã̃o de "Estado-Membro" no Regulamento ver LEHMANN Daniel (2013) "Die EU-ErbVO: Babylon in Brüssel und Berlin". Zeitschrift für die Steuer- und Erbrechtspraxis, 2, p. 25 . 


\subsection{Residência habitual como fator principal de conexão}

A aplicação da lei da última residência habitual do falecido é uma decisão primariamente política. Ela corresponde a uma tendência geral no Direito Internacional Privado europeu de preferir a residência habitual como fator de conexão à nacionalidade. Pois no processo de integração europeu a distinção de pessoas de acordo com a sua nacionalidade é mal vista. Além disso, a aplicação do direito da residência habitual pode incentivar a mobilidade de cidadãos entre os Estados-Membros e deve ajudar a deixar crescer uma "identidade europeia"12. Para os Estados-Membros que até agora usam a nacionalidade do defunto para determinar o direito aplicável à sucessão - como, por exemplo, a Alemanha no art. 25, inciso 1 da Lei de Introdução ao Código Civil - o Regulamento 650/2012 traz um "câmbio de paradigma"13. Ainda assim, vale notar que o Direito Internacional Privado brasileiro manda aplicar, por força do art. 10, caput, da Lei de Introdução às Normas do Direito Brasileiro, a lei do país em que era domiciliado o defunto. Embora as noções de "domicílio" no Direito Internacional Privado brasileiro ${ }^{14}$ e de "residência habitual" no Regulamento 650/2012 não tenham o mesmo significado, a solução brasileira está muito mais perto do art. 21, inciso 1 Regulamento 650/2012 que a do art. 25, inciso 1 da Lei de Introdução ao Código Civil alemã.

\section{a) Conceituação de "residência habitual"}

Uma das questões centrais do Regulamento 650/2012 é saber sob quais circunstâncias uma pessoa tem a sua residência habitual num determinado Estado. Os Considerandos 23 e 24 tentam explicar de maneira abrangente quais os parâmetros para esta análise.

Num primeiro momento, cabe lembrar que o conceito de "residência habitual" é um conceito autônomo ${ }^{15}$ do Regulamento

12 Ver MANSEL Heinz-Peter (2006) "Vereinheitlichung des Internationalen Erbrechts in der Europäischen Gemeinschaft - Kompetenzfragen und Regelungsgrundsätze". In: ARKAN Sabih, YONGALIK Aynur, SIT Basak (eds.) Prof. Dr. Tugrul Ansay'a Armagan, p. 185, 208 210 e LORENZ Stefan (2012) "Erbrecht in Europa - Auf dem Weg zu kollisionsrechtlicher Rechtseinheit". Zeitschrift für die gesamte erbrechtliche Praxis, 2, p. 39, 43-44.

13 Ver a profunda análise de SONNENTAG Michael (2012) "Das Europäische Internationale Erbrecht im Spannungsfeld zwischen der Anknüpfung an die Staatsangehörigkeit und den gewöhnlichen Aufenthalt". Europäisches Wirtschafts- und Steuerrecht, 11, p. 457, 459-465. Além disso, ver KINDLER Peter (2010) "Vom Staatsangehörigkeits- zum Domizilprinzip: das künftige internationale Erbrecht der Europäischen Union". Praxis des Internationalen Privat- und Verfahrensrechts, 1, p. 44, 47 e KUNZ Lena (2012) "Die neue europäische Erbrechtsverordnung - ein Überblick (Teil 1)". Zeitschrift für Gemeinschaftsprivatrecht, 3, p. 208, 210.

14 Sobre o conceito de domicílio no direito brasileiro ver NORDMEIER Carl Friedrich (2008) Zulässigkeit und Bindungswirkung gemeinschaftlicher Testamente im Internationalen Privatrecht, p. 129-139.

15 SCHAUB Renate (2013) “Die EU-Erbrechtsverordnung”. In: MUSCHELER Karlheinz (ed.) Hereditare - Jahrbuch für Erbrecht und Schenkungsrecht, 3, p. 91, 112. 
650/2012. O aplicador de direito está impedido, pois, de recorrer ao entendimento de um Estado-Membro ou ao entendimento do Estado - seja um Estado-Membro, seja um Estado terceiro - em que o defunto possivelmente tivesse a sua última residência habitual ${ }^{16}$.

No mais, parecia desejável - no interesse de uma melhor coerência - desenvolver um conceito de "residência habitual" que pudesse ser usado em todo Direito Internacional Privado da União Europeia. Infelizmente, o legislador europeu trilhou outro caminho. Como se lê no Considerando 23, frases 2 e 3, para a determinação da residência habitual deve-se avaliar de maneira global as circunstâncias da vida do falecido durante os anos anteriores ao óbito e no momento do óbito, contemplando os objetivos específicos do Regulamento 650/2012. Disto decorre que a conceituação da residência habitual tem de ser feita especificamente para o Direito Internacional Privado das sucessões quão lamentável do ponto de vista da coerência do Direito Internacional Privado unional isto seja ${ }^{17}$.

O ponto de partida para a análise é a "permanência" do falecido no Estado em causa. A permanência demanda a presença física - uma presença que, como reza o Considerando 23, frase 3, deve revelar "uma relação estreita e estável” da pessoa com o Estado em questão. Portanto, a mera situação de bens ou a sua detenção, desacompanhada pela presença da pessoa, não gera uma residência habitual. Se uma pessoa transfere a maioria dos seus bens de um Estado para outro (p. ex., para poupar imposto) sem atualmente viver no Estado para o qual transferiu os bens, ela não estabelece a sua residência habitual neste Estado.

Uma constelação comum é a divergência do lugar do trabalho com o lugar da vida social. O Considerando 24, frase 2, dá como exemplo o caso de uma pessoa que, por razões profissionais ou econômicas, foi viver no estrangeiro a fim de aí trabalhar por um longo período, mas tem mantido uma relação estreita e estável com o seu Estado de origem, no qual se situam o centro de interesses da sua família e a sua vida social. Numa tal situação, a residência habitual fica, de acordo com o Considerando 24, frase 3, no Estado de origem. É possível deduzir disto, para a determinação da residência habitual, a prevalência do Estado com o qual o defunto tinha laços familiares e pessoais sobre o Estado com o qual o defunto tinha vínculos profissionais ${ }^{18}$.

16 Exemplo: Caso uma autoridade polonesa tenha de avaliar se o defunto tinha a sua última residência habitual em Angola, ela não pode recorer ao entendimento de "residência habitual" nem do direito polonês nem do direito angolano.

17 De acordo com DÖRNER Heinrich (2012) "EuErbVO: Die Verordnung zum Internationalen Erb- und Erbverfahrensrecht ist in Kraft!”. Zeitschrift für Erbrecht und Vermögensnachfolge, 10, p. 505, 510, a cláusula de escape do art. 21, inciso 2 Regulamento 650/2012 oferece flexibilidade suficiente para evitar um desenvolvimento de um conceito de "residência habitual" particular para fins do Regulamento 650/2012. Os Considerandos 23 e 24 indicam o contrário.

18 DÖRNER Heinrich (2012) "EuErbVO: Die Verordnung zum Internationalen Erb- und Erbverfahrensrecht ist in Kraft!”. Zeitschrift für Erbrecht und Vermögensnachfolge, 10, p. 505, 510. 
Neste contexto, surge a pergunta se existem pessoas sem "residência habitual". Partindo do texto da lei, é bem imaginável que uma pessoa possa não residir habitualmente em Estado algum, embora circule em diferentes Estados. Ainda assim, o art. 21 Regulamento 650/2012 pressupõe que cada pessoa tenha uma residência habitual. Pois um ponto de conexão subsidiário - como, por exemplo, a presença fática ${ }^{19}$ - não é encontrado na norma ${ }^{20}$. Além disso, o Considerando 24, frases 3 e 4, contempla este caso, mencionando que, sob estas circunstâncias, a nacionalidade da pessoa ou o local da situação dos seus principais bens poderiam ser "um fator especial" na apreciação de todas as circunstâncias fáticas. Desta maneira, o legislador europeu dá a entender que, para fins do Regulamento 650/2012, uma pessoa sem residência habitual não existe ${ }^{21}$.

Pode-se pensar, ainda, na solução inversa: Se a pessoa circula em diferentes Estados, ela poderia ter várias residências habituais. Ainda assim, da análise acima feita não só decorre, no meu entender, que, para fins do Regulamento 650/2012, uma pessoa possa não ter residência habitual alguma, mas também que ela não posa ter mais que uma única residência habitual ao mesmo tempo ${ }^{22}$.

Um outro problema na determinação da residência habitual é a relevância de elementos subjetivos. Surge a pergunta se a vontade da pessoa de residir em um determinado lugar deve ser levada em consideração. Por um lado, a constituição de uma residência habitual não pressupõe uma vontade jurídica comparável à que é necessária para celebrar um negócio jurídico ${ }^{23}$. Por outro lado, parece difícil negar qualquer influência de elementos subjetivos ${ }^{24}$. Isto é, sobretudo,

19 A simples presença, em alemão "schlichter Aufenthalt", é usada, de vez em quando, no Direito Internacional Privado alemão como ponto de conexão, caso a pessoa não tenha uma residência habitual (em alemão: "gewöhnlicher Aufenthalt"). Ver VON BAR Christian, MANKOWSKI Peter (2003) Internationales Privatrecht Band I - Allgemeine Lehren. 2. ed. p. 568-569.

20 A cláusula de escape do art. 21, inciso 2 Regulamento 650/2012 exige uma relação mais estreita com um Estado diferente do Estado em que o falecido tinha sua residência habitual. Portanto, ela presupõe uma residência habitual.

21 Em sentido divergente, KUNZ Lena (2012) "Die neue europäische Erbrechtsverordnung - ein Überblick (Teil 1)". Zeitschrift für Gemeinschaftsprivatrecht, 3, p. 208, 210, afirmando que podem existir casos nos quais a residência habitual é indeterminável. Sem posição manifesta, com base na Proposta do Regulamento, SCHURIG Klaus (2010) "Das internationale Erbrecht wird europäisch - Bemerkungen zur kommenden Europäischen Verordnung". In: BERNREUTHER Jörn, FREITAG Robert, LEIBLE Stefan, SIPPEL Harald, WANITZEK Ulrike. Festschrift für Ulrich Spellenberg. p. $343,346$.

22 Em sentido convergente, DÖRNER Heinrich (2012) "EuErbVO: Die Verordnung zum Internationalen Erb- und Erbverfahrensrecht ist in Kraft!". Zeitschrift für Erbrecht und Vermögensnachfolge, 10, p. 505, 510. Reflexões em sentido divergente encontram-se em SCHAUB Renate (2013) "Die EU-Erbrechtsverordnung". In: MUSCHELER Karlheinz (ed.) Hereditare - Jahrbuch für Erbrecht und Schenkungsrecht, 3. p. 91, 113.

23 DÖRNER Heinrich (2012) "EuErbVO: Die Verordnung zum Internationalen Erb- und Erbverfahrensrecht ist in Kraft!". Zeitschrift für Erbrecht und Vermögensnachfolge, 10, p. 505, 510. 24 LEHMANN Daniel (2012) "Die EU-Erbrechtsverordnung zur Abwicklung grenzüberschreitender Nachlässe". Deutsches Steuerrecht, p. 2085, 2087; SCHAUB Renate (2013) "Die EU- 
problemático em constelações nas quais a pessoa sofra de uma doença mental e, portanto, não seja mais capaz de determinar por vontade própria o lugar em que quer viver ${ }^{25}$. Além disso, cabe lembrar que o defunto, no momento da abertura da sucessão, não é mais capaz de informar a sua vontade. Portanto, a determinação de elementos subjetivos sempre demanda a análise de fatos objetivos para que a existência de uma vontade do defunto possa ser determinada. Por outro lado, a avaliação global das circunstâncias da vida do falecido, o que exige o Considerando 23, frase 2, pode incluir momentos subjetivos sobretudo quando avaliam-se as "razões" da permanência num Estado, ao que o Considerando mencionado se refere expressamente.

\section{b) Cláusula de escape}

O Regulamento 650/2012 conta com uma cláusula de escape, que foi inserida no texto legal relativamente tarde, já durante o processo legislativo. De acordo com o art. 21, inciso 2 Regulamento 650/2012, se houver "uma relação manifestamente mais estreita" com um Estado diferente do Estado da última residência habitual, é aplicada, a título excepcional, a lei do Estado com o qual esta relação existe. Dado o fato de que o conceito de "residência habitual" já oferece flexibilidade suficiente para levar em consideração todas as circunstâncias da vida do defunto, podia-se questionar a necessidade de uma cláusula de escape adicional ${ }^{26}$. Pois, via de regra, a residência habitual indica o Estado com o qual o defunto tinha a relação mais estreita. Portanto, o âmbito de aplicação do art. 21, inciso 2 Regulamento 650/2012 parece relativamente estreito ${ }^{27}$. Quanto a uma possível aplicação da norma, o Considerando 25, frase 1, menciona o caso em que o falecido tenha se mudado para o Estado da sua residência habitual muito pouco tempo antes da sua morte e todas as circunstâncias do caso indiquem que ele tinha uma relação manifestamente mais estreita com outro Estado.

Do ponto de vista do aplicador do direito, uma cláusula de escape parece vantajosa, pois é impossível obter informações do defunto pessoalmente ${ }^{28} \mathrm{e}$, portanto, os fatos nos quais a decisão sobre a

\footnotetext{
Erbrechtsverordnung". In: MUSCHELER Karlheinz (ed.) Hereditare - Jahrbuch für Erbrecht und Schenkungsrecht, 3, p. 91, 113 e SÜß Rembert (2009) "Der Vorschlag der EG-Kommission zu einer Erbrechtsverordnung (Rom IV-Verordnung) vom 14. Oktober 2009". Zeitschrift für Erbrecht und Vermögensnachfolge, 12, p. 342, 344. Ver também RODRÍGUEZ-URÍA SUÁREZ Isabel (2013) "La ley aplicable a las sucesiones mortis causa en el Reglamento (UE) 650/2012". InDret - Revista para el Análisis del Derecho, 2, p. 1, 15.

25 ODERSKY Felix (2013) "Die Europäische Erbrechtsverordnung in der Gestaltungspraxis". notar, 1, p. 3, 5 .

26 DUTTA Anatol (2013) "Das neue internationale Erbrecht der Europäischen Union - Eine erste Lektüre der Erbrechtsverordnung". Zeitschrift für das gesamte Familienrecht, 1, p. 4, 8.

27 KOHLER Christian, PINTENS Walter (2012) "Entwicklungen im europäischen Familienund Erbrecht 2011-2012". Zeitschrift für das gesamte Familienrecht, 18, p. 1425, 1427.

28 WILKE Felix M. (2012) "Dasinternationale Erbrecht nach der neuen EU-Erbrechtsverordnung".
} 
residência habitual está baseada podem ser duvidosos. Ainda assim, o Considerando 25, frase 2, sublinha que a relação manifestamente mais estreita não deverá tornar-se um fator de conexão subsidiário caso se revele complexa a determinação da residência habitual.

\subsection{Unidade da sucessão}

O regulamento está baseado no princípio da unidade da sucessão $0^{29}$, isto é, o direito determinado como sendo aplicável rege "o conjunto da sucessão", como reza o art. 21, inciso 1 Regulamento 650/2012. Portanto, o Regulamento não promove uma distinção, quanto à lei aplicável, entre coisas móveis ou coisas imóveis. A título de exemplo: deixando um falecido, que morreu com residência habitual na Itália, uma casa situada Espanha, a sucessão quanto a esta casa é regida pela lei italiana. Esta solução mostra-se vantajosa, dado o fato de que o princípio contrário, o do fracionamento da herança - de acordo com o qual as coisas imóveis são distribuídas de acordo com a lei do lugar onde se encontrem e as coisas móveis de acordo com a lei a última residência habitual do falecido - provocaria questões de difícil qualificação, dificultaria o cálculo das legítimas e complicaria a realização dos direitos dos credores do falecido ${ }^{30}$. Além disso, incrementariam a complexidade e os custos do planejamento da sucessão, pois a pessoa que quisesse organizar a distribuição dos seus bens para depois da sua morte teria de levar em consideração diversas leis materiais e coordená-las. Embora o princípio do fracionamento da herança seja seguido, sobretudo, nos Estados da common law e na França ${ }^{31}$, desde o início dos trabalhos no Regulamento as vantagens do princípio da unidade da sucessão foram sublinhadas ${ }^{32}$,

Recht der internationalen Wirtschaft, 9, p. 601, 605.

29 JAYME Erik (2011) "Zur Reichweite des Erbstatuts". In: REICHELT Gerte, RECHBERGER Walter H. Europäisches Erbrecht : Zum Verordnungsvorschlag der Europäischen Kommission zum Erb- und Testamentsrecht, p. 27-40 e RODRÍGUEZ-URÍA SUÁREZ Isabel (2013) "La ley aplicable a las sucesiones mortis causa en el Reglamento (UE) 650/2012". InDret - Revista para el Análisis del Derecho, 2, p. 1, 9-10.

30 LAGARDE Paul (2012) "Les principes de base du nouveau règlement européen sur les successions". Revue critique de droit international privé, 4, p. 691, 696. Em língua portuguesa, ver MACHADO João Baptista (2009) Lições de Direito Internacional Privado. 3. ed. p. 434-435. 31 O princípio foi atenuado no direito francês, pois permite-se o reenvio. Constou Sobretudo em situações nas quais a lei do lugar da situação de um bem imóvel remete para a lei da última residência habitual do defunto, chega-se à unidade da sucessão por reenvio. Ver JAYME Erik (2011) "Zur Reichweite des Erbstatuts". In: REICHELT Gerte, RECHBERGER Walter H. Europäisches Erbrecht : Zum Verordnungsvorschlag der Europäischen Kommission zum Erb- und Testamentsrecht, p. 27, 29.

32 DÖRNER Heinrich, HERTEL Christian, LAGARDE Paul, RIERING Wolfgang (2005) "Auf dem Weg zu einem europäischen Internationalen Erb- und Verfahrensrecht". Praxis des Internationalen Privat- und Verfahrensrechts, 1, p. 1, 4 e MAX PLANCK INSTITUTE FOR COMPARATIVE AND INTERNATIONAL PRIVATE LAW (2010) "Comments on the European Commission's Proposal for a Regulation of the European Parliament and of the Council on jurisdiction, applicable law, recognition and enforcement of decisions and authentic instruments in matters of succession and the creation of a European Certificate of Succession". 
o que, no final das contas, virou um princípio básico do Regulamento.

\subsection{Reenvio}

Os Regulamentos de Direito Internacional Privado editados pela União Europeia excluem, em grande medida, o reenvio ${ }^{33}$. Nesta linha de entendimento, o art. 26 da proposta do Regulamento também o fez, mandando aplicar as normas materiais do Estado cuja lei for indicada como sendo aplicável, com exclusão das normas de Direito Internacional Privado. Na doutrina, houve o entendimento de que a admissão do reenvio em casos nos quais o defunto morreu com residência habitual num Estado terceiro seria de grande utilidade para garantir a harmonia internacional de decisões ${ }^{34}$ e poderia facilitar a distribuição do processo de herança entre os tribunais dos Estados-Membros ${ }^{35}$. Sob esta ótica, é de se saudar que o art. 34 Regulamento 650/2012 permite o reenvio, embora não o tenha feito de uma forma abrangente.

Como ponto de partida, vale notar que a questão do reenvio põe-se somente em casos nos quais a lei de um Estado, que não é vinculado pelo Regulamento 650/2012, é determinada pelas normas do Regulamento 650/2012 como sendo a lei aplicável. Pois entre os Estados nos quais vigora o Regulamento 650/2012 não pode existir uma situação em que o Direito Internacional Privado do Estado A remeta para a lei do Estado B enquanto o Direito Internacional Privado do Estado B remeta para o Estado C, ou remeta de volta para o Estado $A^{36}$. Pelo contrário, a identidade das normas de Direito Internacional Privado no âmbito do direito das sucessões - dada pelo fato de que no Estado A, bem como no Estado B, vigora o Regulamento 650/2012 - tem como consequência que as normas jurídicas em vigor nos dois Estados sempre remetam para a mesma lei ${ }^{37}$.

Rabels Zeitschrift für ausländisches und internationales Privatrecht, 74, p. 522, 602, 603.

33 Ver SOLOMON Dennis (2012) "Die Renaissance des Renvoi im Europäischen Internationalen Privatrecht”. In: MICHAELSO Ralf, SOLOMON Dennis (edits.) Liber Amicorum Klaus Schurig, p. 237-238. SCHACK Haimo (2013) “Was bleibt vom renvoi?". Praxis des Internationalen Privatund Verfahrensrechts, 4, p. 315, 318-319.

34 KINDLER Peter (2010) "Vom Staatsangehörigkeits- zum Domizilprinzip: das künftige internationale Erbrecht der Europäischen Union". Praxis des Internationalen Privat- und Verfahrensrechts, 1, p. 44, 48-49. Ver uma posição relativizadora em SOLOMON Dennis. Op. cit. p. 237, 248-250. Ver também SCHACK Haimo (2013) "Was bleibt vom renvoi?". Praxis des Internationalen Privat- und Verfahrensrechts, 4, p. 315, 319.

35 JAYME Erik (2011) “Zur Reichweite des Erbstatuts". In: REICHELT Gerte, RECHBERGER Walter H. Europäisches Erbrecht : Zum Verordnungsvorschlag der Europäischen Kommission zum Erb- und Testamentsrecht, p. 27, 39-40.

36 A respeito de somente nestas circunstâncias poder ocorrer um reenvio, ver NEUHAUS Paul Heinrich (1976) Die Grundbegriffe des Internationalen Privatrechts. 2. ed. p. 268-270.

37 SCHACK Haimo (2013) "Was bleibt vom renvoi?" Praxis des Internationalen Privat- und Verfahrensrechts, 4, p. 315, 320 nota que a simplificação da determinação da lei aplicável é outro argumento em favor de excluir o reenvio entre os Estados-Membros. Ainda assim, pelas razões expostas, a determinação da lei aplicável não se tornaria mais complexa se nos dois Estados 
Além disso, cabe sublinhar que, de acordo com o art. 34, inciso 2 Regulamento 650/2012, o reenvio não deve ser admitido, entre outros casos, quando a lei aplicável for determinada pela cláusula de escape do art. 21, inciso 2 Regulamento 650/2012, nem quando o defunto tiver feito uma escolha da lei de acordo com o art. 22 Regulamento 650/2012 ${ }^{38}$.

Em relação aos Estados terceiros, as normas de Direito Internacional Privado desses Estados encontram aplicação de acordo com o art. 34, inciso 1, lit. a) Regulamento 650/2012 quando remetam o caso para a lei de um Estado-Membro. É de ser sublinhado que o texto legal refere-se à "lei de um Estado-Membro", não à lei do foro. Isto tem como consequência, por exemplo, que uma autoridade francesa encarregada de tratar a sucessão de um alemão que morreu com última residência na Arábia Saudita aplicará a lei alemã ${ }^{39}$. Além disso, o texto da norma não distingue entre o reenvio que inclua o Direito Internacional Privado e o reenvio que o exclua. A segunda hipótese resolve-se sem maiores problemas: é aplicada a lei material do EstadoMembro ao qual o Direito Internacional Privado do Estado terceiro remeta o caso. A primeira hipótese, pelo contrário, levanta dúvidas e dificuldades, pois a remissão do Estado terceiro, à primeira vista, inclui o Direito Internacional Privado do Estado-Membro e, com este, as regras do Regulamento 650/2012, que remeteriam, novamente, o caso para o Estado terceiro, que, por sua vez, novamente o remeteria para o Estado-Membro, e assim sucessivamente. Nesta situação, a melhor solução é que se interrompa a "corrente de remissões" depois da primeira remissão pelo Estado terceiro para o Estado-Membro. Como uma harmonia internacional de decisões não é alcançável neste caso, parece ser preferível aplicar a lei do Estado-Membro, que na maioria dos casos é a lex fori ${ }^{40}$.

Se o Direito Internacional Privado do Estado terceiro não remeter para a lei de um Estado-Membro, restam duas hipóteses: na primeira, o Estado terceiro manda aplicar a sua própria lei material. Na segunda, o Estado terceiro remete para um outro Estado terceiro. A primeira hipótese é fácil de solucionar. Se o Estado terceiro aplica a sua própria

vigorasse o Regulamento 650/2012.

38 Sobre a escolha da lei ver abaixo o tópico 4 .

39 Exemplo retirado de LAGARDE Paul (2005) "Les principes de base du nouveau règlement européen sur les successions". Revue critique de droit international privé. 4, p. 691, 705. De acordo com KRÜGER Hilmar (2005) "Internationalrechtliche Probleme in Saudi-Arabien". Praxis des Internationalen Privat- und Verfahrensrechts, 4, p. 386, 387, os tribunais da Arábia Saudita sempre aplicam o seu próprio direito das sucessões mesmo se o caso tenha somente um contato mínimo com o país.

40 Esta solução é defendida com profunda argumentação por SOLOMON Dennis (2012) "Die Renaissance des Renvoi im Europäischen Internationalen Privatrecht”. In: MICHAELS Ralf, SOLOMON Dennis (edits.) Liber Amicorum Klaus Schurig, p. 237, 253. No mesmo sentido está BAJONS Eva-Marlis (2013) "Die EU-ErbrechtsVO: Gleichlauf und Auseinanderfall von forum und ius im Wechselspiel mit Drittstaaten". In: STAMM Jürgen (edit.) Festschrift für Helmut Rüßmann, p. 751, 758. 
lei, é aceito este "reenvio" - que, na verdade, não é um "re-envio", mas sim a aceitação do chamamento feito pelo Regulamento 650/2012 - e encontra aplicação a lei do Estado terceiro. Neste caso, o resultado não diverge do que seja uma remissão ao direito material, sendo a admissibilidade do reenvio uma reflexão meramente teórica.

Mais complexa é a segunda hipótese, o caso do assim chamado "reenvio de segundo grau". Está em questão aqui a situação na qual o Direito Internacional Privado do Estado terceiro, chamado como sendo aplicável pelo Regulamento 650/2012, remete o caso para a lei de um outro Estado terceiro. O art. 34, inciso 1, lit. b) Regulamento 650/2012 ordena que a lei material do segundo Estado terceiro encontre aplicação caso este aplicasse a sua própria lei. Isto lembra, de certo modo, a regra de reconhecimento no estatuto pessoal do Direito Internacional Privado português. O art. 31, inciso 2 do Código Civil português ordena que sejão reconhecidos em Portugal os negócios jurídicos celebrados no país de residência habitual do declarante, em conformidade com a lei desse país, desde que esta se considere competente ${ }^{41}$. No mais, a regra do Regulamento, neste ponto, é de ser aplaudida, pois gera harmonia internacional de decisões entre o primeiro e o segundo Estados terceiros: Se fossem requisitadas a decidir o caso, as autoridades do primeiro Estado terceiro, bem como as do segundo Estado terceiro, aplicariam a lei material do segundo Estado terceiro.

Como o reenvio está admitido somente na medida em que o art. 34 Regulamento 650/2012 permite, decorre que em situações não contempladas pelo art. 34 Regulamento 650/2012 é chamado para a aplicação o direito material do primeiro Estado terceiro ${ }^{42}$. Aqui o legislador europeu infelizmente parece não ter contemplado o caso em que o Direito Internacional Privado do segundo Estado terceiro não aceita o reenvio, mas remete para a lei de um outro Estado-Membro ou até para a lex for ${ }^{43}$. Parece inconsistente permitir o reenvio de acordo com o art. 34, inciso 1, lit. a) Regulamento 650/2012, quando o primeiro Estado terceiro remeter para a lei de um Estado-Membro, mas impedilo se o segundo Estado terceiro o fizer. Além disso, se o segundo Estado

41 Para uma análise abrangente do art. 31, inciso 2 Código Civil português ver NORDMEIER Carl Friedrich (2008) Zulässigkeit und Bindungswirkung gemeinschaftlicher Testamente im Internationalen Privatrecht, p. 102-109. Ainda, MOURA VICENTE Dário (2010) "Sources and Principles of Portuguese Private International Law: An Outline”. In: MOURA VICENTE Dário (edit.) Direito Internacional Privado: Ensaios III, p. 409, 414-415 e NORDMEIER Carl Friedrich (2012) "Stand, Perspektiven und Grenzen der Rechtslagenanerkennung im europäischen Rechtsraum anhand Entscheidungen mitgliedstaatlicher Gerichte". Praxis des Internationalen Privat- und Verfahrensrechts, 1, p. 31, 40.

42 Ver BAJONS Eva-Marlis (2013) "Die EU-ErbrechtsVO: Gleichlauf und Auseinanderfall von forum und ius im Wechselspiel mit Drittstaaten". In: STAMM Jürgen (edit.) Festschrift für Helmut Rüßmann, p. 751, 759.

43 SOLOMON Dennis (2012) "Die Renaissance des Renvoi im Europäischen Internationalen Privatrecht". In: MICHAELS Ralf, SOLOMON Dennis (edits.) Liber Amicorum Klaus Schurig, p. 237, 255-256. 
terceiro remeter para a lex fori, estaremos perante a estranha situação de que as autoridades do forum, isto é, do Estado-Membro em questão, aplicam a lei do primeiro Estado terceiro, enquanto as autoridades dos dois Estados terceiros aplicariam, se fossem chamadas para julgar o caso, a lei do Estado-Membro, quer dizer, a lex fori do ponto de vista do Estado-Membro.

\section{A ESCOLHA DA LEI}

O Regulamento prevê a possibilidade de a pessoa escolher a lei aplicável para regular toda a sua sucessão ${ }^{44}$. Sedes materiae é o art. 22 Regulamento 650/2012. Diferente de outros ramos do Direito Internacional Privado europeu ${ }^{45}$, permite-se aqui somente uma escolha limitada: só pode ser escolhida a lei da nacionalidade da pessoa. $\mathrm{O}$ legislador europeu justificou esta limitação com o objetivo de assegurar a conexão entre o falecido e a lei escolhida e de evitar que seja escolhida uma lei com a intenção de frustrar as expectativas legítimas das pessoas com direito à legítima ${ }^{46}$. A nacionalidade da pessoa aparece como vínculo suficientemente forte de uma pessoa com um ordenamento jurídico para que a distribuição dos bens dessa pessoa depois da sua morte seja submetida às leis materiais deste, se a pessoa assim quiser ${ }^{47}$.

\subsection{A diferença entre a escolha da lei e a disposição por morte}

Num primeiro momento, deve-se distinguir entre a escolha da lei e a disposição por morte. De acordo com o art. 3, inciso 1. lit. d) Regulamento 650/2012, o termo "disposição por morte" é, para fins do Regulamento, um conceito geral que abrange o testamento, o testamento de mão comum e o pacto sucessório ${ }^{48}$. A escolha de lei, por sua vez, é

44 Para uma análise aprofundada da escolha da lei no Regulamento 650/2012 ver NORDMEIER Carl Friedrich (2013) "Grundfragen der Rechtswahl in der neuen EU-Erbrechtsverordnung eine Untersuchung des Art. 22 ErbRVO". Zeitschrift für Gemeinschaftsprivatrecht, 3, p. 148-155. Além disso, ver LEITZEN Mario (2013) "Die Rechtswahl nach der EuErbVO". Zeitschrift für Erbrecht und Vermögensnachfolge, 3, p. 128-132; LAGARDE Paul (2012) "Les principes de base du nouveau règlement européen sur les successions". Revue critique de droit international privé, 4, p. 691, 719-722 e DUTTA Anatol (2013) "Das neue internationale Erbrecht der Europäischen Union - Eine erste Lektüre der Erbrechtsverordnung". Zeitschrift für das gesamte Familienrecht, 1, p. $4,8-9$.

45 Sobretudo no Direito das Obrigações contratuais permite o art. 3 Regulamento (CE) $\mathrm{N}^{\circ}$ 593/2008 do Parlamento Europeu e do Conselho de 17 de Junho de 2008 ("Roma I") a escolha livre da lei aplicável ao contrato.

46 Ver Considerando 38 Regulamento 650/2012.

47 Sobre o princípio da nacionalidade no Direito Internacional Privado na pós-modernidade ver JAYME Erik (2012) Zugehörigkeit und kulturelle Identität: Die Sicht des Internationalen Privatrechts, p. 24-30. Como bem nota JAYME, Op. cit., p. 27, as leis de nacionalidade que determinam os presupostos para a aquisição e a perda da nacionalidade são baseadas em valores que não têm origem no Direito Internacional Privado das sucessões.

48 Sobre a lei aplicável à disposição por morte ver abaixo o tópico 5. 
a uma declaração jurídica de uma pessoa com o conteúdo de que a sua sucessão por morte seja regulada pela lei de um determinado Estado ${ }^{49}$. Embora o art. 22, inciso 2 Regulamento 650/2012 demande, quanto à forma da escolha, que ela seja feita expressamente numa declaração que revista a forma de uma disposição por morte ou resulte dos termos de uma tal disposição, a escolha da lei não é uma disposição por morte e pode ser feita de forma isolada desta. Ainda assim, na grande maioria dos casos a escolha da lei estará contida numa disposição por morte. Pois a escolha é uma ferramenta de planejar a sucessão e quase sempre fica acompanhada por outros meios de planejamento, contidos num disposição por morte.

Para mais, é importante distinguir entre a escolha da lei aplicável à sucessão de uma pessoa de acordo com o art. 22 Regulamento 650/2012 e a escolha da lei que rege a admissibilidade e a validade material de uma disposição por morte diferente de um pacto sucessório de acordo com o art. 24, inciso 2 Regulamento 650/2012 ou da escolha da lei que rege a admissibilidade, a validade material e os efeitos vinculativos de um pacto sucessório de acordo com o art. 25, inciso 3 Regulamento 650/2012 $2^{50}$. O primeiro é a escolha do "estatuto sucessório real" (tatsächliches Erbstatut), enquanto o segundo diz respeito ao "estatuto sucessório hipotético" (hypothetisches Erbstatut) ${ }^{51}$. Este estatuto sucessório hipotético regula somente os aspetos mencionados - a admissibilidade, a validade material e, para o pacto sucessório, os efeitos vinculativos - e é determinado, na falta de uma escolha, pela aplicação das regras do Regulamento sob a hipótese que o testador tivesse falecido no dia em que fez a disposição por morte ${ }^{52}$.

\subsection{A nacionalidade como ponto de conexão}

Elegível é a lei da nacionalidade da pessoa. A pergunta sobre se uma pessoa é nacional de um determinado Estado está fora do âmbito de aplicação do Regulamento 650/2012. Ela deve ser resolvida, como reza o Considerando 41, frase 1, "a título preliminar". Estamos, pois, perante uma questão prévia $^{53}$, a ser respondida pela lei do Estado cuja

49 NORDMEIER Carl Friedrich (2013) "Grundfragen der Rechtswahl in der neuen EU-Erbrechtsverordnung - eine Untersuchung des Art. 22 ErbRVO”. Zeitschrift für Gemeinschaftsprivatrecht, 3, p. 148, 151.

50 Sobre esta escolha ver NORDMEIER Carl Friedrich (2013) "Erbverträge in der neuen EUErbrechtsverordnung: zur Ermittlung des hypothetischen Erbstatuts nach Art. 25 ErbRVO". Zeitschrift für die Steuer- und Erbrechtspraxis, 5, p. 112, 115-116.

51 LECHNER Kurt (2013) "Erbverträge und gemeinschaftliche Testamente in der neuen EUErbrechtsverordnung". Neue Juristische Wochenschrift, 1, p. 26, 27.

52 Daí resulta, portanto, a expressão "estatuto sucessório hipotético".

53 Isto fica mais claro em outras versões linguísticas do Considerando 41. As versões francesa (question préliminaire), inglesa (preliminary question) e espanola (cuestión preliminar) usam o termo técnico. 
nacionalidade está discutida no caso $^{54}$. Ainda assim, o Considerando 41 , frase 2 indica um entendimento autônomo de nacionalidade para fins do Regulamento 650/2012, demandando o "pleno respeito pelos princípios gerais da União Europeia”. Por causa disso, parece viável, por exemplo, desconsiderar - para a determinação da lei aplicável de acordo com o art. 22 Regulamento 650/2012 - a perda de uma nacionalidade se esta infringir os princípios gerais da União Europeia ${ }^{55}$.

\section{a) A nacionalidade no momento da escolha e no momento da morte}

O art. 21, inciso 1 Regulamento 650/2012 permite a escolha da lei do Estado de que a pessoa é nacional no momento em que faz a escolha ou no momento do óbito ${ }^{56}$. Enquanto a primeira opção é bem fácil de compreender, a segunda levanta dúvidas quanto à sua necessidade prática ${ }^{57}$. Da perspectiva de uma pessoa que planeja a sua sucessão, ela tem somente relevância se uma mudança de nacionalidade estiver prevista. Em outras palavras: A escolha da lei da nacionalidade no momento do óbito fica somente relevante se esta divergir da nacionalidade no momento da escolha da lei. Portanto, no momento de escolher a pessoa tem de saber já de antemão que mudará de nacionalidade e qual será a nova nacionalidade que adquirirás8. Uma tal situação parece pouco comum. Ainda assim, a regra pode facilitar a determinação da lei aplicável se o defunto fez uma escolha, mas a sua nacionalidade no momento da escolha é difícil de determinar. Caso a lei escolhida seja a do Estado ao qual pertencia o defunto no momento da sua morte, pode ficar em aberto a sua nacionalidade no momento da escolha ${ }^{59}$.

$54 \mathrm{O}$ problema lembra o "reenvio à qualificação" que remete uma questão, que seja relevante para uma norma do Direito Internacional Privado, para um determinado ordenamento jurídico, p. ex., a questão se uma coisa é móvel ou imóvel à lex rei sitae. Sobre o "reenvio à qualificação" ver JAYME Erik (1976) "Zur Qualifikationsverweisung im internationalen Privatrecht”. Zeitschrift für Rechtsvergleichung, 17, p. 93-108.

55 NORDMEIER Carl Friedrich (2013) "Grundfragen der Rechtswahl in der neuen EUErbrechtsverordnung - eine Untersuchung des Art. 22 ErbRVO”. Zeitschrift für Gemeinschaftsprivatrecht, 3, p. $148,149$.

56 Detalhadamente, ver o que diz em RODRÍGUEZ-URÍA SUÁREZ Isabel (2013) "La ley aplicable a las sucesiones mortis causa en el Reglamento (UE) 650/2012". InDret - Revista para el Análisis del Derecho, 2, p. 1, 12-13.

57 WILKEFelix M. (2012) "DasinternationaleErbrecht nach der neuen EU-Erbrechtsverordnung". Recht der internationalen Wirtschaft, 9, p. 601, 605.

58 Discute-se se, para a escolha da lei do Estado ao qual pertence a pessoa no momento do óbito, é necessária a designação concreta (p. ex.: "Escolho a lei francesa.") ou se basta a designação abstrata (p. ex.: "Esolho a lei do Estado de que serei nacional no momento do meu óbito."). No meu entender, a designação abstrata é suficiente. Ver NORDMEIER Carl Friedrich (2013) "Grundfragen der Rechtswahl in der neuen EU-Erbrechtsverordnung - eine Untersuchung des Art. 22 ErbRVO". Zeitschrift für Gemeinschaftsprivatrecht, 3, p. 148, 150.

59 WILKE Felix M. (2012) "DasinternationaleErbrecht nach derneuen EU-Erbrechtsverordnung". Recht der internationalen Wirtschaft, 9, p. 601, 606. 


\section{b) Múltiplas nacionalidades e pessoas sem nacionalidade}

Uma pessoa com múltiplas nacionalidades pode escolher a lei de qualquer dos Estados de que é nacional, como reza o art. 21, inciso 1, frase 2 Regulamento 650/2012. Esta possibilidade refere-se às nacionalidades no momento da escolha bem como no momento do óbito ${ }^{60}$. Ao prever a escolha, o legislador europeu levou em consideração a jurisprudência do Tribunal de Justiça da União Europeia. No caso García Avello ${ }^{61}$, a Corte concedeu - para fins do Direito Internacional Privado do nome - para uma pessoa com múltiplas nacionalidades um direito à escolha entre as leis dos Estados aos quais ela pertence. Em seguida, esta linha de entendimento foi transferida pela Corte, no acórdão Hadadi ${ }^{62}$, ao Direito Internacional Privado Processual.

O Regulamento não prevê uma escolha da lei para pessoas sem nacionalidade. Ainda assim, vários Estados-Membros da União Europeia, entre eles a Alemanha, são Estados-partes da Convenção de Nova Iorque de 28.9.1954 sobre o estatuto dos apátridas, que, de acordo com o art. 75 Regulamento 650/2012, prevalece sobre as regras do Regulamento. $\mathrm{O}$ art. 12, inciso 1 da citada Convenção ordena que para pessoas sem nacionalidade o ponto de conexão relevante é o domicílio e, para pessoas sem domicílio, a sua residência ${ }^{63}$. Disto decorre que uma pessoa sem nacionalidade pode escolher a lei do Estado no qual tem domicílio no momento da escolha ou no momento do seu óbito. Não tendo domicílio, pode optar pela lei do lugar da sua residência no momento da escolha ou no momento do seu óbito.

\subsection{A escolha}

Art. 22, inciso 2 Regulamento 650/2012 prevê duas formas de fazer a escolha: de maneira expressa ou de maneira tácita. Enquanto a escolha expressa não provoca maiores problemas de interpretação ${ }^{64}$, a escolha tácita, que tem de resultar dos termos duma disposição por morte, demanda a análise detalhada da disposição em questão. O Considerando 39 , frase 2 , menciona, a título de exemplo, a referência a normas específicas da lei do Estado da nacionalidade do defunto. Além disso, podem servir de indicação a uma escolha tácita a língua em que a

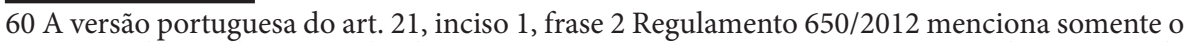
momento da escolha, não o do óbito. Mas uma comparação com outras versões linguísticas da norma mostra claramente que trata-se de um erro de redação da versão portuguesa.

61 Tribunal de Justiça da União Europeia. Acórdão de 02.10.2003. Processo C-148/02. Coletânea de Jurisprudência 2003, I-11613. Caso Garcia Avello ./. Estado Belga.

62 Tribunal de Justiça da União Europeia. Acórdão de 16.07.2009. Processo C-168/08. Caso Laszlo Hadadi ./. Csilla Marta Mesko,épouse Hadadi.

$63 \mathrm{O}$ conceito de "residência" da Convenção não deve ser confundido com o conceito de "residência habitual" do Regulamento.

64 Quanto à designação da lei escolhida ver a nota de rodapé número 58. 
disposição está redigida, motivos do testador mencionados na disposição ou a adaptação da sucessão às exigências da lei da nacionalidade do testador $^{65}$. Cabe mencionar, ainda, que os parâmetros da escolha tácita têm de ser determinados de maneira autônoma-europeia, não de acordo com a lei escolhida ${ }^{66}$.

Como já mencionado, é necessário que, de acordo com o art. 22, inciso 2 Regulamento 650/2012, a escolha respeite a forma de uma disposição por morte. De maneira geral, isto significa que a escolha tem de observar a forma de uma das leis indicadas no art. 27 Regulamento $650 / 2012^{67}$. Restam dúvidas sobre as exigências quanto à forma de uma escolha da lei feita que seja feita oralmente. Estas são devidas ao fato de que o art. 1, inciso 2, lit. f) Regulamento 650/2012 exclui a validade formal das disposições por morte feitas oralmente do âmbito de aplicação do Regulamento 650/2012 ${ }^{68}$.

Quanto à validade material do ato pelo qual foi feita a escolha, ordena o art. 22, inciso 3 Regulamento 650/2012 que esta seja regulada pela lei escolhida. Encontra aqui aplicação o assim chamado "bootstrap principle", já conhecido, por exemplo, pelo art. 3, inciso 5 Regulamento Roma I ${ }^{69}$ : É suficiente que haja uma primeira impressão de que tenha havido uma escolha da lei para que a lei possivelmente escolhida possa julgar a validade material da escolha.

\section{AS DISPOSIÇÕES POR MORTE}

Nos arts. 24-27 Regulamento 650/2012 estão contidas as normas sobre a determinação do direito aplicável às disposições por morte. Como já referido, o art. 3, inciso 1, lit. d) Regulamento 650/2012 define que disposições por morte são o testamento, o testamento de mão comum e o pacto sucessório. Ainda assim, os arts. 24 e 25 Regulamento 650/2012 não seguem esta diferenciação. Enquanto o art. 25 Regulamento 650/2012 trata dos pactos sucessórios, o art. 24 Regulamento 650/2012

65 NORDMEIER Carl Friedrich (2013) "Grundfragen der Rechtswahl in der neuen EUErbrechtsverordnung - eine Untersuchung des Art. 22 ErbRVO”. Zeitschrift für Gemeinschaftsprivatrecht, 3, p. 148, 152 .

66NORDMEIERCarlFriedrich(2013) “GrundfragenderRechtswahlinderneuenEU-Erbrechtsverordnung - eine Untersuchung des Art. 22 ErbRVO". Zeitschrift für Gemeinschaftsprivatrecht, 3, p. 148, 151-152. Um entendimento contrário encontra-se em LEITZEN Mario (2013) "Die Rechtswahl nach der EuErbVO". Zeitschrift für Erbrecht und Vermögensnachfolge, 3, p. 128, 129.

67 DUTTA Anatol (2013) "Das neue internationale Erbrecht der Europäischen Union - Eine erste Lektüre der Erbrechtsverordnung". Zeitschrift für das gesamte Familienrecht, 1. p. 4, 8 e LEITZEN Mario (2013) "Die Rechtswahl nach der EuErbVO". Zeitschrift für Erbrecht und Vermögensnachfolge, 3 , p. $128,129$.

68 Sobre o problema ver NORDMEIER Carl Friedrich (2013) "Grundfragen der Rechtswahl in der neuen EU-Erbrechtsverordnung - eine Untersuchung des Art. 22 ErbRVO”. Zeitschrift für Gemeinschaftsprivatrecht, 3, p. 148, 153.

69 Ver a referência na nota de rodapé número 45. 
ocupa-se com testamentos e testamentos de mão comum ${ }^{70}$. Em seguida, o art. 26 Regulamento 650/2012 descreve o termo "validade material" para todas as disposições por morte e o art. 27 Regulamento 650/2012 regula a forma de todas estas disposições, mas somente se lavradas por escrito. A validade formal das disposições por morte feitas oralmente está fora do âmbito de aplicação do Regulamento 650/2012, como ordena o art. 1, inciso 2, lit. f) Regulamento 650/2012.

É necessário, pois, distinguir, por um lado, entre os três tipos de disposição por morte e, por outro lado, entre a validade formal e a validade material de uma disposição por morte.

\subsection{O testamento de mão comum e o pacto sucessório}

Do ponto de vista da prática forense alemã, a distinção entre o testamento de mão comum ${ }^{71}$ e o pacto sucessório é de grande importância. O testamento de mão comum, regulado nos parágrafos 2.265-2.272 Código Civil alemão, bem como o pacto sucessório, cujo regime legal encontra-se nos parágrafos 2.274-2.302 Código Civil alemão, são de uso muito frequente. A grande maioria dos testamentos de mão comum têm força vinculante de acordo com os parágrafos $2.270 \mathrm{e}$ 2.271 Código Civil alemão ${ }^{72}$. O pacto sucessório é vinculativo conforme o parágrafo 2.279 Código Civil alemão. Ainda assim, somente o art. 25 Regulamento 650/2012, que trata dos pactos sucessórios, menciona os "efeitos vinculativos". No art. 24 Regulamento 650/2012, que rege os testamentos ou testamentos de mão comum com efeitos vinculativos, não se lê uma regra específica para tanto.

As noções de "pacto sucessório" e de "testamento de mão comum" estão definidas no próprio Regulamento 650/2012. Como reza o art. 3, inciso 1, lit. b) Regulamento 650/2012, o pacto sucessório é "um acordo, incluindo um acordo resultante de testamentos mútuos, que crie, altere ou anule, com ou sem contrapartida, direitos na herança ou heranças futuras de uma ou mais pessoas que sejam partes no acordo". Por "testamento de mão comum" entende-se, de acordo com o art. 3, inciso 1, lit. c) Regulamento 650/2012, um "testamento redigido por duas ou mais pessoas num único ato".

\footnotetext{
70 Já o título do art. 24 Regulamento 650/2012, "Disposições por morte diferentes dos pactos sucessórios", não é de grande rigor sistemático. Melhor teria sido colocar "Testamentos e testamentos de mão comum". Ver a crítica de WILKE Felix M. (2012) "Das internationale Erbrecht nach der neuen EU-Erbrechtsverordnung”. Recht der internationalen Wirtschaft, 9, p. $601,606$.

71 Sobre o testamento de mão comum no Regulamento 650/2012 ver NORDMEIER Carl Friedrich (2012) "EuErbVO: Neues Kollisionsrecht für gemeinschaftliche Testamente". Zeitschrift für Erbrecht und Vermögensnachfolge, 10, p. 513-519.

72 Sobre os diferentes tipos de testamento de mão comum no direito alemão, ver NORDMEIER Carl Friedrich (2008) Zulässigkeit und Bindungswirkung gemeinschaftlicher Testamente im Internationalen Privatrecht. p. 20-30.
} 
Há quem defenda a inclusão do testamento de mão comum com força vinculativa do direito alemão na noção de "pacto sucessório". O testamento de mão comum compreenderia, assim, testamentos mútuos no sentido da definição do art. 3, inciso 1, lit. b) Regulamento 650/2012 $2^{73}$. No meu entender, este entendimento não respeita as definições contidas no art. 3 , inciso 1 , lit. b) e c) Regulamento $650 / 2012^{74}$. Pois o testamento de mão comum do direito alemão, em quase todos os casos, é redigido num único ato e, portanto, enquadra-se na definição do art. 3, inciso 1, lit. c) Regulamento 650/2012. Mas ele não é necessariamente um "acordo" no sentido do art. 3, inciso 1, lit. b) Regulamento 650/2012. Além disso, não pode invocar-se o princípio da interpretação autônoma do Direito da União Europeia ${ }^{75}$, de acordo com o qual uma noção contida no direito unional não pode ser interpretada da maneira igual à interpretação estabelecida no direito somente de um Estado-Membro; pelo contrário, o intérprete tem de levar em consideração sentidos divergentes que estejam presentes em outros Estados-Membros bem como os objetivos específicos do direito unional. Embora decorra disto que a noção de "testamento de mão comum" do direito alemão não corresponda necessariamente à mesma noção no Regulamento 650/2012, a interpretação autônoma não permite ignorar as definições contidas no próprio direito unional - no caso, as definições no art. 3, inciso 1 , lit. b) e lit. c) Regulamento 650/2012. Levando em consideração estas definições unionais, o testamento de mão comum do direito alemão enquadra-se no conceito unional de testamento de mão comum, mas não no conceito do pacto sucessório. Além disso, os direitos materiais de muitos Estados-Membros conhecem a diferenciação entre o testamento de mão comum e o pacto sucessório. Não se encontra o entendimento de que um pacto sucessório seja uma disposição por morte com força vinculativa enquanto o testamento de mão comum não a tenha ${ }^{76}$.

73 Ver a discussão abrangente em LEHMANN Daniel (2013) "Die EU-ErbVO: Babylon in Brüssel und Berlin". Zeitschrift für die Steuer- und Erbrechtspraxis, 2, p. 25-29. Ainda, em LECHNER Kurt (2013) "Erbverträge und gemeinschaftliche Testamente in der neuen EUErbrechtsverordnung". Neue Juristische Wochenschrift, 1, p. 26, 27 e em LEITZEN Mario (2013) “Die Rechtswahl nach der EuErbVO". Zeitschrift für Erbrecht und Vermögensnachfolge, 3, p. 128, 130. Um entendimento amplo da noção de „pacto sucessório“ é defendido também em DUTTA Anatol (2013) "Das neue internationale Erbrecht der Europäischen Union - Eine erste Lektüre der Erbrechtsverordnung". Zeitschrift für das gesamte Familienrecht, 1, p. 4, 10.

74 NORDMEIER Carl Friedrich (2013) "Erbverträge und nachlassbezogene Rechtsgeschäfte in der EuErbVO - eine Begriffsklärung". Zeitschrift für Erbrecht und Vermögensnachfolge, 3, p. 117, 120 e NORDMEIER Carl Friedrich (2013) "Gemeinschaftliche Testamente in der EU-ErbRVO". Neue Juristische Wochenschrift aktuell, 8, p. 14. Esta linha de entendimento é defendida também por SIMON Ulrich, BUSCHBAUM Markus (2012) "Die neue EU-Erbrechtsverordnung". Neue Juristische Wochenschrift, 33, p. 2393, 2396.

75 Sobre a interpretação do Direito Internacional Privado de origem unional ver JAEGER JUNIOR Augusto (2012) Europeização do direito internacional privado: caráter universal da lei aplicável e outros contrastes com o ordenamento jurídico brasileiro.

76 Argumentos adicionais encontram-se em NORDMEIER Carl Friedrich (2013) "Erbverträge und nachlassbezogene Rechtsgeschäfte in der EuErbVO - eine Begriffsklärung". Zeitschrift für 


\subsection{O estatuto sucessório hipotético}

Como já foi referido, além do estatuto sucessório real o Regulamento 650/2012 conhece o estatuto sucessório hipotético. A criação de um tal estatuto particular baseia-se na ideia de que uma pessoa que pretenda organizar antecipadamente a sua sucessão por uma disposição por morte tenha de saber definitivamente qual o direito aplicável à disposição. Se a validade de uma disposição por morte fosse julgada de acordo com a lei da última residência habitual do defunto, uma mudança da residência habitual depois de ser feita a disposição poderia afetar a validade desta. Para impedir uma tal influência, a admissibilidade e a validade material de uma disposição por morte - e, quando tratar-se de um pacto sucessório, seus efeitos vinculativos - são regidos pela lei que seria aplicável se a pessoa tivesse falecido no dia em que fez a disposição. Na mesma ideia e na mesma técnica legislativa está baseado o art. 26, inciso 5, frase 1 da Lei de Introdução ao Código Civil alemão ${ }^{77}$.

No ponto de partida, a determinação do estatuto sucessório hipotético não parece causar mais dificuldades que a determinação do estatuto sucessório real. Ainda assim, pode-se duvidar se a cláusula de escape do art. 21, inciso 2 Regulamento 650/2012 é de ser aplicada. O Considerando 51 indica que este não é o caso, pois ele reza que a referência para determinar o estatuto sucessório hipotético "deverá ser entendida como uma referência à lei do Estado de residência habitual da pessoa em causa”. Ainda assim, entendo que a cláusula de escape deve ser aplicada ao determinar o estatuto sucessório hipotético ${ }^{78}$. A limitação do Considerando 51 não encontra suporte no texto legal.

O reenvio do art. 34 Regulamento 650/2012 deve ser respeitado no momento de se determinar o estatuto sucessório hipotético. Para saber se o Direito Internacional Privado de um Estado terceiro remete de maneira relevante para uma outra lei, deve-se presumir a morte da pessoa que fez a disposição também ao se verificar o reenvio do Estado terceiro $^{79}$.

\footnotetext{
Erbrecht und Vermögensnachfolge, 3, p. 117, 120.

77 NORDMEIER Carl Friedrich (2013) Zulässigkeit und Bindungswirkung gemeinschaftlicher Testamente im Internationalen Privatrecht, p. 51-54 e RODRÍGUEZ-URIA SUÁREZ Isabel (2013) "La ley aplicable a las sucesiones mortis causa en el Reglamento (UE) 650/2012". InDret - Revista para el Análisis del Derecho, 2, p. 1, 22.

78 Ver a discussão em NORDMEIER Carl Friedrich (2013) "Erbverträge in der neuen EUErbrechtsverordnung: zur Ermittlung des hypothetischen Erbstatuts nach Art. 25 ErbRVO". Zeitschrift für die Steuer- und Erbrechtspraxis, 5, p. 112, 113-114.

79 NORDMEIER Carl Friedrich (2013) "Erbverträge in der neuen EU-Erbrechtsverordnung: zur Ermittlung des hypothetischen Erbstatuts nach Art. 25 ErbRVO”. Zeitschrift für die Steuerund Erbrechtspraxis, 5, p. 112, 114.
} 


\subsection{A escolha da lei aplicável à disposição por morte}

Para melhorar a segurança jurídica ainda mais, a escolha da lei aplicável a uma disposição por morte é permitida de acordo com os arts. 24, inciso 2, e 25, inciso 3, Regulamento 650/2012. Esta escolha refere-se à admissibilidade da disposição por morte, à sua validade material e, quando está em questão um pacto sucessório, aos seus efeitos vinculativos. Podem ser escolhidas as leis mencionadas no art. 22 Regulamento 650/2012, isto é, as leis da nacionalidade ou das nacionalidades da pessoa que faz a disposição no momento de a fazer ou no momento da sua morte. Uma particularidade encontra-se para o pacto sucessório que diz respeito à sucessão de várias pessoas (pacto sucessório multilateral): É elegível a lei que uma das pessoas cuja herança está em causa pudesse escolher de acordo com o art. 22 Regulamento $650 / 2012$. Se, por exemplo, uma italiana e um alemão fazem um pacto sucessório, podem optar pelo direito alemão como sendo aplicável ao pacto sucessório inteiro ${ }^{80}$.

\subsection{A forma da disposição por morte}

A validade formal das disposições por morte está regulada para todas as disposições no art. 27 Regulamento 650/2012. Ainda assim, vigora em 14 Estados-Membros - entre eles a Alemanha - a Convenção da Haia de 5 de Outubro de 1961 sobre os Conflitos de Leis em Matéria de Forma das Disposições Testamentárias. Esta Convenção prevalece sobre as regras do Regulamento, como ordena o art. 75, inciso 1, frase 2 Regulamento 650/2012 ${ }^{81}$. Como o art. 27 Regulamento 650/2012 quer regular a validade formal duma disposição por morte de maneira coerente com a Convenção ${ }^{82}$, e, para atingir este objetivo, simplesmente incorporou no Regulamento as regras de conexão da Convenção, não haverá uma divergência prática na aplicação do art. 27 Regulamento 650/2012 e da Convenção. Vale lembrar, porém, que a Convenção não abrange pactos sucessórios, enquanto o art. 27 Regulamento 650/2012 refere-se a esta disposição por morte também ${ }^{83}$. Portanto, ao determinar a lei aplicável à validade formal de um pacto sucessório, os EstadosMembros que são Estados partes da Convenção - bem como os que não

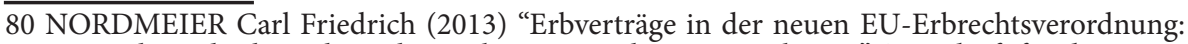
zur Ermittlung des hypothetischen Erbstatuts nach Art. 25 ErbRVO”. Zeitschrift für die Steuerund Erbrechtspraxis, 5, p. 112, 116.

81 DÖRNER Heinrich (2012) "EuErbVO: Die Verordnung zum Internationalen Erb- und Erbverfahrensrecht ist in Kraft!". Zeitschrift für Erbrecht und Vermögensnachfolge, 10, p. 505, 511. 82 Ver o Considerando número 52, frase 1 do Regulamento.

83 RODRÍGUEZ-URÍA SUÁREZ Isabel (2013) "La ley aplicable a las sucesiones mortis causa en el Reglamento (UE) 650/2012”. InDret - Revista para el Análisis del Derecho, 2, p. 1, 39 e WILKE Felix M. (2012) "Das internationale Erbrecht nach der neuen EU-Erbrechtsverordnung". Recht der internationalen Wirtschaft, 9, p. 601, 607. 
são - aplicam o Regulamento.

\section{REGRAS PARTICULARES}

O Regulamento 650/2012 contêm várias regras para questões particulares. A título de exemplo, discute-se em seguida o problema dos comorientes, regulado no art. 32 Regulamento 650/2012, e da herança vaga, à qual diz respeito o art. 33 Regulamento 650/2012.

\subsection{Comorientes}

Um problema clássico do Direito Internacional Privado das Sucessões é o dos comorientes com estatutos sucessórios divergentes. Este surge se duas ou mais pessoas morrem sob circunstâncias nas quais não é possível determinar a ordem dos falecimentos, como, por exemplo, em acidentes de trânsito ou em situações de guerra. Caso as pessoas mortas possam ser herdeiras umas das outras, as leis de sucessão materiais normalmente providenciam normas sobre como a "morte simultânea" influencia a ordem de herdeiros ${ }^{84}$. Se as leis aplicáveis às sucessões das pessoas envolvidas divergirem, soluções incompatíveis podem ocorrer. Se, por exemplo, morrem esposos, podia acontecer que a lei aplicável à sucessão do marido previsse que a mulher herdasse todos os bens dos dois, enquanto a lei aplicável à sucessão da mulher previsse que o marido herdasse tudo. Para a solução de tal conflito, o art. 32 Regulamento 650/2012 ordena que ne $\neg$ nhum dos falecidos deva ter qualquer direito na sucessão do outro. Cabe frisar que o art. 32 Regulamento 650/2012 diz respeito somente a situações nas quais as leis envolvidas regulem o problema da morte simultânea de forma diferente ou não o regulem. Portanto, se as leis materiais aplicáveis cheguem à mesma solução, é esta que vale ${ }^{85}$.

Com esta solução, o art. 32 Regulamento 650/2012 não contém uma regra de Direito Internacional Privado, mas sim uma regra material ${ }^{86}$. Pois a norma não indica a lei material aplicável, mas decide o problema por si, dando a solução material. Embora a União Europeia

84 Há ordenamentos jurídicos que excluem direitos sucessórios entre pessoas que morram simultaneamente. Outros deixam a pessoa mais jovem herdar da mais antiga. Ver DUTTA Anatol (2009) "Succession and Wills in the Conflict of Laws on the Eve of Europeanisation". Rabels Zeitschrift für ausländisches und internationales Privatrecht, 74, p. 547, 598-599.

85 Ver o Considerando número 55 do Regulamento citado e WILKE Felix M. (2012) "Das internationale Erbrecht nach der neuen EU-Erbrechtsverordnung". Recht der internationalen Wirtschaft, 9, p. 601, 607.

86 DUTTA Anatol (2013) "Das neue internationale Erbrecht der Europäischen Union - Eine erste Lektüre der Erbrechtsverordnung". Zeitschrift für das gesamte Familienrecht, 1. p. 4, 11; REMDE Julia (2012) "Die Europäische Erbrechtsverordnung nach dem Vorschlag der Kommission vom 14. Oktober 2009". Rheinische Notar-Zeitschrift, 1, p. 65, 77 e WILKE Felix M. (2012) "Das internationale Erbrecht nach der neuen EU-Erbrechtsverordnung". Recht der internationalen Wirtschaft, 9, p. 601, 607. 
só tenha competência, de acordo com o art. 81, inciso 2, lit. c Tratado sobre o Funcionamento da União Europeia, para regular o Direito Internacional Privado, o art. 32 Regulamento 650/2012 pode ser baseado nesta competência, dado o fato de que o problema tem a sua raiz na esfera do Direito Internacional Privado ${ }^{87}$. Ainda assim, uma solução de Direito Internacional Privado teria sido possível como alternativa, por exemplo, se fosse elegida a aplicação da lei material do Estado com o qual todas as pessoas mortas simultaneamente tivessem uma relação mais estreita.

Outra observação diz respeito ao âmbito de aplicação do Regulamento 650/2012. As questões relacionadas com odesaparecimento, a ausência ou a morte presumida de uma pessoa singular estão fora do âmbito de aplicação do Regulamento, como reza o art. 1, inciso 2, lit. c) Regulamento $650 / 2012^{88}$. É necessário, pois, distinguir entre normas materiais que regulem a morte presumida e as que digam respeito às sucessões de pessoas mortas em ordem desconhecida.

\subsection{Herança vaga}

A lei aplicável à sucessão rege, de acordo com o art. 23, inciso 2, lit. b) Regulamento 650/2012 a determinação dos beneficiários. Portanto, ao estatuto sucessório cabe decidir quem é herdeiro, bem como se herdeiros existem, sobretudo. Caso não haja uma pessoa física ou jurídica que herde, a herança é "vaga", "vacante" ou "sem herdeiros". Neste caso, o poder público pode aproveitar-se da herança. Do ponto de vista comparatista, este resultado é incontestado; por exemplo, no direito brasileiro, o art. 1.822 Código Civil prevê que os bens passarão ao domínio do Município ou do Distrito Federal se localizados nas respectivas circunscrições ou ao domínio da União quando situados em território federal. O direito alemão, de acordo com o art. 1.936 do Código Civil alemão, faz herdeiro o Estado no qual o defunto teve o seu último domicílio ou sua última residência habitual. Não tendo domicílio ou residência habitual, a União herda.

Ainda assim, existem duas maneiras de como o poder público ocupa os bens que o defunto deixou ${ }^{89}$. De acordo com a primeira, o

87WILKEFelixM.(2013) “Dasinternationale Erbrecht nach der neuenEU-Erbrechtsverordnung”. Recht der internationalen Wirtschaft, 9, p. 601, 607, defende uma competência acessória da União Europeia. Em sentido contrário está RODRÍGUEZ-URÍA SUÁREZ Isabel (2013) "La ley aplicable a las sucesiones mortis causa en el Reglamento (UE) 650/2012". InDret - Revista para el Análisis del Derecho, 2, p. 1, 41.

88 DUTTA Anatol (2013) "Das neue internationale Erbrecht der Europäischen Union - Eine erste Lektüre der Erbrechtsverordnung". Zeitschrift für das gesamte Familienrecht, 1, p. 4, 11 e SCHAUB Renate (2013) "Die EU-Erbrechtsverordnung". In: MUSCHELER Karlheinz (edit.) Hereditare - Jahrbuch für Erbrecht und Schenkungsrecht, 3, p. 91, 123.

89 DÖRNER Heinrich (2012) "Der Zugriff des Staates auf erbenlosen Nachlass - Fiskuserbrecht oder hoheitliche Aneignung?". Praxis des Internationalen Privat- und Verfahrensrechts, 3, p. 235, 
Estado é o "último herdeiro", isto é, caso não haja outro herdeiro, o Estado herda. Esta é a solução do direito alemão no art. 1.936 Código Civil alemão. A segunda, conhecida, sobretudo, nos direitos que pertencem à família jurídica da common law ${ }^{90}$, considera os bens deixados como pertencentes a ninguém (bona vacantia) e permitem que o Estado em que os bens se encontrem, os se aproprie. O primeiro modelo pode ser chamado de "modelo da herança", já o segundo de "modelo da apropriação".

Em casos com elementos transfronteiriços, os dois modelos podem conflitar. Existem dois tipos de conflitos: O primeiro aparece quando o direito aplicável à sucessão segue o modelo da herança, mas o defunto deixou bens situados num Estado em que vigora o modelo da apropriação. O segundo diz respeito à constelação inversa, prevendo como direito aplicável à sucessão um direito à apropriação pelo Estado enquanto o Estado nos quais os bens estão localizados adota o modelo da herança ${ }^{91}$. No primeiro, surge a pergunta se o Estado em que os bens estão situados pode exercer seu direito de apropriação, embora o Estado cuja lei é o estatuto sucessório seja herdeiro de todos os bens do defunto. No segundo, fica em aberto o que acontecerá com os bens situados no Estado que segue o modelo da herança. Pois o direito de apropriação do Estado cuja lei é o estatuto sucessório limita-se aos bens situados no seu próprio território ${ }^{92}$. O Estado da situação dos bens, pelo contrário, não se considera herdeiro, sendo a sua lei material das sucessões não aplicável ao caso.

$\mathrm{O}$ art. 33 Regulamento 650/2012 soluciona a primeira das duas constelações mencionadas.

De acordo com esta norma, o estatuto sucessório não impede que um Estado-Membro possa apropriar-se, nos termos da sua própria lei $\mathrm{i}^{93}$, dos bens da herança situados no seu território, desde que os credores tenham o direito de obter a satisfação dos seus créditos a partir da totalidade dos bens da herança. A segunda constelação não encontra

\section{6-237.}

90 Por exemplo, no direito do Estado de Nova Iorque, Estados Unidos da América, o $\$$ 200 Abandoned Property Law ordena que bens sem herdeiros revertam ao Estado. Em detalhe, ver NORDMEIER Carl Friedrich (2011) "New Yorker Heimfallrecht an erbenlosen Nachlassgegenständen und deutsches Staatserbrecht". Praxis des Internationalen Privat- und Verfahrensrechts, 6, p. 535-538.

91 DÖRNER Heinrich (2012) "Der Zugriff des Staates auf erbenlosen Nachlass - Fiskuserbrecht oder hoheitliche Aneignung?". Praxis des Internationalen Privat- und Verfahrensrechts, 3, p. 235, 236-237 e DUTTA Anatol (2013) "Das neue internationale Erbrecht der Europäischen Union - Eine erste Lektüre der Erbrechtsverordnung”. Zeitschrift für das gesamte Familienrecht, 1, p. 4, 11-12.

92 NORDMEIER Carl Friedrich (2011) "New Yorker Heimfallrecht an erbenlosen Nachlassgegenständen und deutsches Staatserbrecht". Praxis des Internationalen Privat- und Verfahrensrechts, 6, p. 535, 538.

93 Isto é, de acordo com o seu direito de apropriação. 
uma solução ${ }^{94}$, porque o Estado da situação dos bens não se apropriaria de nada, mas herdaria, e o direito material do Estado que fornece o estatuto sucessório não seria capaz de "impedir" outros Estados no tratamento dos bens. Esta constelação deveria ser solucionada com um adaptação no nível do Direito Internacional Privado, aplicando-se a lex rei sitae para a sucessão dos bens.

\section{CONSIDERAÇÕES FINAIS}

O novo Regulamento 650/2012 torna europeizado de maneira abrangente o Direito Internacional Privado das Sucessões. As normas sobre a determinação do direito aplicável à sucessão são claras nas suas estruturas gerais: a residência habitual como ponto de conexão principal, a possibilidade de escolher a lei da nacionalidade, e a unidade da sucessão. Mas muitas questões que dizem respeito a perguntas particulares ainda estão em aberto. Além disso, o Regulamento 650/2012, já pelo seu mero tamanho, é um desafio para a prática forense. A partir de 17 de agosto de 2015, o Regulamento 650/2012 encontrará aplicação nos tribunais e enfrentará a sua prova prática. Com o direito das sucessões, mais um ramo do direito foi harmonizado no crescente processo da europeização do Direito Internacional Privado.

\section{REFERÊNCIAS BIBLIOGRÁFICAS}

BAJONS Eva-Marlis (2013) "Die EU-ErbrechtsVO: Gleichlauf und Auseinanderfall von forum und ius im Wechselspiel mit Drittstaaten". In: STAMM Jürgen (edit.) Festschrift für Helmut Rüßmann. Saarbrücken: Juris-Verlag, p. 751-762.

BUSCHBAUMMarkus,SIMONUlrich(2012)“EuErbVO:DasEuropäische Nachlasszeugnis". Zeitschrift für Erbrecht und Vermögensnachfolge, 10, p. 525-530.

DÖRNER Heinrich (2012) "Der Zugriff des Staates auf erbenlosen Nachlass - Fiskuserbrecht oder hoheitliche Aneignung?". Praxis des Internationalen Privat- und Verfahrensrechts, 3, p, 235-238.

DÖRNER Heinrich (2012) "EuErbVO: Die Verordnung zum Internationalen Erb- und Erbverfahrensrecht ist in Kraft!". Zeitschrift für Erbrecht und Vermögensnachfolge, 10, p. 505-513.

DÖRNER Heinrich, HERTEL Christian, LAGARDE Paul, RIERING Wolfgang (2005) "Auf dem Weg zu einem europäischen Internationalen Erb- und Verfahrensrecht". Praxis des Internationalen Privat- und Verfahrensrechts, 1, p. 1-8.

94 DUTTA Anatol (2013) "Das neue internationale Erbrecht der Europäischen Union - Eine erste Lektüre der Erbrechtsverordnung". Zeitschrift für das gesamte Familienrecht, 1, p. 4, 12 e RODRÍGUEZ-URÍA SUÁREZ Isabel (2013) "La ley aplicable a las sucesiones mortis causa en el Reglamento (UE) 650/2012”. InDret - Revista para el Análisis del Derecho, 2, p. 1, 41. 
DUTTA Anatol (2009) "Succession and Wills in the Conflict of Laws on the Eve of Europeanisation". Rabels Zeitschrift für ausländisches und internationales Privatrecht, 74, p. 547-606.

DUTTA Anatol (2013) "Das neue internationale Erbrecht der Europäischen Union - Eine erste Lektüre der Erbrechtsverordnung”. Zeitschrift für das gesamte Familienrecht, 1, p. 4-15.

JAEGER JUNIOR Augusto (2012) Europeização do direito internacional privado: caráter universal da lei aplicável e outros contrastes com o ordenamento jurídico brasileiro. Curitiba: Juruá Ediotra, 672 p.

JAEGER JUNIOR Augusto, NORDMEIER Carl Friedrich (2013) "Comunitarização do Direito Internacional Privado: paulatina harmonização de um âmbito jurídico”. In: SOUZA DEL'OLMO Florisbal de, COLER GIMENEZ Charlise Paula, MARCONATTO DAMO CERVI Taciana (edits.) Direitos Fundamentais e Cidadania: a busca pela efetividade. Campinas: Editora Millennium, p. 131-156.

JAYME Erik (1976) "Zur Qualifikationsverweisung im internationalen Privatrecht”. Zeitschrift für Rechtsvergleichung, 17, p. 93-108.

JAYME Erik (2011) "Zur Reichweite des Erbstatutsv. In: REICHELT Gerte, RECHBERGER Walter H. Europäisches Erbrecht: Zum Verordnungsvorschlag der Europäischen Kommission zum Erb- und Testamentsrecht. Wien: Jan Sramek Verlag, p. 27-40.

JAYME Erik (2012) Zugehörigkeit und kulturelle Identität: Die Sicht des Internationalen Privatrechts. Göttingen: Wallenstein Verlag, 62 p.

KINDLER Peter (2010) "Vom Staatsangehörigkeits- zum Domizilprinzip: das künftige internationale Erbrecht der Europäischen Union”. Praxis des Internationalen Privat- und Verfahrensrechts, 1, p. 44-50.

KOHLER Christian, PINTENS Walter (2012) "Entwicklungen im europäischen Familien- und Erbrecht 2011-2012". Zeitschrift für das gesamte Familienrecht, 18, p. 1425-1432.

KRÜGER Hilmar (2005) "Internationalrechtliche Probleme in SaudiArabien". Praxis des Internationalen Privat- und Verfahrensrechts, 4, p. 386-389.

KUNZ Lena (2012) "Die neue europäische Erbrechtsverordnung - ein Überblick (Teil 1)". Zeitschrift für Gemeinschaftsprivatrecht, 3, p. 208-212. LAGARDE Paul (2012) "Les principes de base du nouveau règlement européen sur les successions". Revue critique de droit international privé, 4, p. 691-732.

LECHNER Kurt (2013) "Erbverträge und gemeinschaftliche Testamente in der neuen EU-Erbrechtsverordnung". Neue Juristische Wochenschrift, 1, p. 26-28.

LEHMANN Daniel(2012) “DieEU-Erbrechtsverordnung zur Abwicklung grenzüberschreitender Nachlässe”. Deutsches Steuerrecht, p. 2085-2089. LEHMANN Daniel (2012) "Die EU-ErbVO: Babylon in Brüssel und Berlin”. Zeitschrift für die Steuer- und Erbrechtspraxis, 2, p. 25-30. 
LEITZEN Mario (2013) “Die Rechtswahl nach der EuErbVO”. Zeitschrift für Erbrecht und Vermögensnachfolge, p. 128-132.

LORENZ Stefan (2012) "Erbrecht in Europa - Auf dem Weg zu kollisionsrechtlicher Rechtseinheit". Zeitschrift für die gesamte erbrechtliche Praxis, 2, p. 39-49.

MACHADO João Baptista (2009) Lições de Direito Internacional Privado. 3ra. Coimbra: Almedina Editora. 458 p.

MANSEL Heinz-Peter (2006) "Vereinheitlichung des Internationalen Erbrechts in der Europäischen Gemeinschaft - Kompetenzfragen und Regelungsgrundsätze". In: ARKAN Sabih, YONGALIK Aynur, SIT Basak (edits.) Prof. Dr. Tugrul Ansay’a Armagan, p. 185-226.

MAX PLANCK INSTITUTE FOR COMPARATIVE AND INTERNATIONAL PRIVATE LAW (2010) "Comments on the European Commission's Proposal for a Regulation of the European Parliament and of the Council on jurisdiction, applicable law, recognition and enforcement of decisions and authentic instruments in matters of succession and the creation of a European Certificate of Succession". Rabels Zeitschrift für ausländisches und internationales Privatrecht, 74, p. 522-720.

MOURA VICENTE Dário (2010) "Sources and Principles of Portuguese Private International Law: An Outline”. In: MOURA VICENTE Dário (edit.) Direito Internacional Privado: Ensaios III. Coimbra: Almedina Editora, p. 409-431.

NEUHAUS Paul Heinrich (1976) Die Grundbegriffe des Internationalen Privatrechts. 2. ed. Tübingen: Mohr Siebeck, 488 p.

NORDMEIER Carl Friedrich (2008) Zulässigkeit und Bindungswirkung gemeinschaftlicher Testamente im Internationalen Privatrecht. Tübingen: Mohr Siebeck, 385 p.

NORDMEIER Carl Friedrich (2011) "New Yorker Heimfallrecht an erbenlosen Nachlassgegenständen und deutsches Staatserbrecht". Praxis des Internationalen Privat- und Verfahrensrechts, 6, p. 535-541.

NORDMEIER Carl Friedrich (2012) "EuErbVO: Neues Kollisionsrecht für gemeinschaftliche Testamente". Zeitschrift für Erbrecht und Vermögensnachfolge, 10, p. 513-519.

NORDMEIER Carl Friedrich (2012) "Stand, Perspektiven und Grenzen der Rechtslagenanerkennung im europäischen Rechtsraum anhand Entscheidungen mitgliedstaatlicher Gerichte". Praxis des Internationalen Privat- und Verfahrensrechts, 1, p. 31-40.

NORDMEIER Carl Friedrich (2013) "Erbverträge in der neuen EUErbrechtsverordnung: zur Ermittlung des hypothetischen Erbstatuts nach Art. 25 ErbRVO". Zeitschrift für die Steuer- und Erbrechtspraxis, 5, p. 112118.

NORDMEIER Carl Friedrich (2013) "Erbverträge und nachlassbezogene Rechtsgeschäfte in der EuErbVO - eine Begriffsklärung". Zeitschrift für Erbrecht und Vermögensnachfolge, 3, p. 117-124. 
NORDMEIER Carl Friedrich (2013) "Gemeinschaftliche Testamente in der EU-ErbRVO”. Neue Juristische Wochenschrift aktuell, 8, p. 14.

NORDMEIER Carl Friedrich (2013) "Grundfragen der Rechtswahl in der neuen EU-Erbrechtsverordnung - eine Untersuchung des Art. 22 ErbRVO”. Zeitschrift für Gemeinschaftsprivatrecht, 3, p. 148-155.

ODERSKY Felix (2013) "Die Europäische Erbrechtsverordnung in der Gestaltungspraxis". Notar, 1, p. 3-9.

REMDE Julia (2012) "Die Europäische Erbrechtsverordnung nach dem Vorschlag der Kommission vom 14. Oktober 2009". Rheinische NotarZeitschrift, 1, p. 65-85.

RODRÍGUEZ-URÍA SUÁREZ Isabel (2013) "La ley aplicable a las sucesiones mortis causa en el Reglamento (UE) 650/2012". InDret Revista para el Análisis del Derecho, 2, p. 1-58.

ROTH Wulf-Henning (2011) "Der Vorschlag einer Verordnung zur Regelung des Internationalen Erbrechts". In: SCHMOECKEL Mathias, OTTE Gerhard (edits.) Europäische Testamentsformen. Baden-Baden: Nomos-Verlag, p. 13-30.

SCHACK Haimo (2013) "Was bleibt vom renvoi?". Praxis des Internationalen Privat- und Verfahrensrechts, 4, p. 315-320.

SCHAUB Renate (2013) "Die EU-Erbrechtsverordnung". In: MUSCHELER Karlheinz (edit.) Hereditare - Jahrbuch für Erbrecht und Schenkungsrecht. Tübingen: Mohr Siebeck, 3, p. 91-131.

SCHMIDT Jan Peter (2013) "Die kollisionsrechtliche Behandlung dinglich wirkender Vermächtnisse". Rabels Zeitschrift für ausländisches und internationales Privatrecht, 77, p. 2-30.

SCHURIG Klaus (2010) "Das internationale Erbrecht wird europäisch - Bemerkungen zur kommenden Europäischen Verordnung”. In: BERNREUTHER Jörn, FREITAG Robert, LEIBLE Stefan, SIPPEL Harald, WANITZEK Ulrike (dir). Festschrift für Ulrich Spellenberg. München: Sellier European Law Publishers,p. 343-353.

SIMON Ulrich, BUSCHBAUM Markus (2012). "Die neue EUErbrechtsverordnung". Neue Juristische Wochenschrift, 33, p. 2393-2398.

SOLOMON Dennis (2012) "Die Renissance des Renvoi im Europäischen Internationalen Privatrecht". In: MICHAELS Ralf, SOLOMON Dennis (edits.) Liber Amicorum Klaus Schurig. München: Sellier European Law Publishers, p. 237-263.

SONNENTAG Michael (2012) "Das Europäische Internationale Erbrecht im Spannungsfeld zwischen der Anknüpfung an die Staatsangehörigkeit und den gewöhnlichen Aufenthalt". Europäisches Wirtschafts- und Steuerrecht, 11, p. 457-469.

SÜß Rembert (2009) "Der Vorschlag der EG-Kommission zu einer Erbrechtsverordnung (Rom IV-Verordnung) vom 14. Oktober 2009". Zeitschrift für Erbrecht und Vermögensnachfolge, 12, p. 342-348.

VOLLMER Peter W. (2012) "Die neue europäische Erbrechtsverordnung - 
ein Überblick". Zeitschrift für die Steuer-und Erbrechtspraxis, 9, p. 227-234. VON BAR Christian, MANKOWSKI Peter (2003) Internationales Privatrecht Band I - Allgemeine Lehren. 2 ed. München: C. H. Beck, 745 p. WILKE Felix M. (2012) "Das internationale Erbrecht nach der neuen EUErbrechtsverordnung". Recht der internationalen Wirtschaft, 9, p. 601-609. WILSCH Harald (2012) "EuErbVO: Die Verordnung in der deutschen Grundbuchpraxis". Zeitschrift für Erbrecht und Vermögensnachfolge, 10, p. 530-532. 